\title{
EL ARCHIPIÉLAGO DEL PERRO Philippe Claudel
}

\section{Patricia Cafasso Maberino}

Licenciada en Psicología de la UDELAR

Miembro Habilitante de AUDEPP

Correo electrónico: patriciacafasso@gmail.com

ORCID: 0000-003-1520-384X 


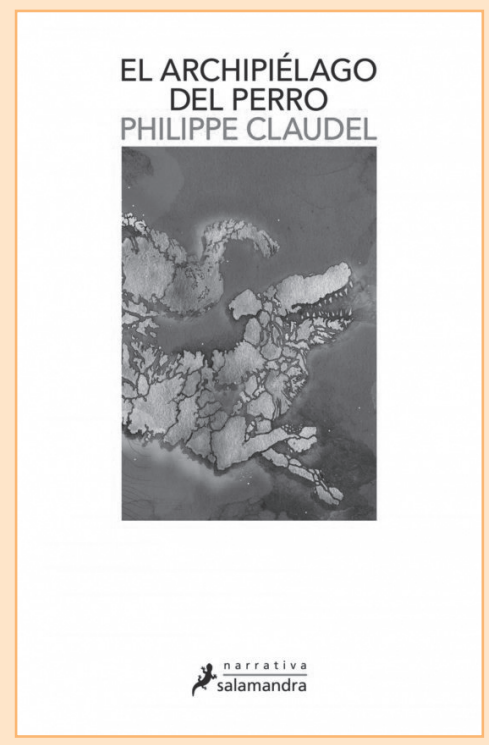

Título: El archipiélago del perro Autor: Phillipe Claudel Año: 2019

Editorial: Salamandra

Ciudad: Barcelona

Páginas: 205 
A sus 58 años, Phillipe Claudel ha recorrido los caminos de la docencia, de la escritura y del cine. Maestro, profesor, guionista y director, publicó numerosos libros, muchos de los cuales han sido traducidos a distintos idiomas.

Con algunas de sus novelas ganó los premios: Francia Televisión 2000, por J'abandonne; Bourse Goncourt de la Nouvelle en 2003, por su libro de relatos Les petites mécaniques; Renaudot en 2003, otorgado por periodistas y críticos literarios, por Almas grises; y Goncourt de los Estudiantes en 2007, con El informe de Brodeck. De sus películas, Hace mucho que te quiero obtuvo en 2009 el Premio César de la Academia del Cine Francés a la mejor ópera prima y el premio BAFTA (British Academy of Film and Television Arts) al mejor film de habla no inglesa.

En sus novelas Phillipe Claudel construye lugares compuestos de manera tal que, si buscamos su ubicación precisa, no necesariamente la podremos encontrar. Sin embargo, nos resultarán familiares. Ese es el caso de El archipiélago del perro, que no es ningún lugar y, a la vez, pueden serlo todos. Se insinúa en el Mediterráneo, cercano a África, y estaría conformado por un grupo de islas que, con la suficiente distancia o perspectiva, puede asemejarse a un perro. Su única isla habitada, donde se desarrolla la historia de esta novela, equivaldría a las fauces abiertas de un can que muestra sus colmillos, cual atemorizador guardián en la entrada al mundo de los muertos, y que, sobre todo, impide la salida.

Su descripción nos sitúa en un lugar de extrañeza, quizás precisamente porque, ya desde el gesto natural inicial de pretender asir sus coordenadas, nos adviene la perplejidad de un lugar sin nombre real, a la vez dispuesto en un tiempo incierto que - lejos de plantear una distancia de 
ajenidad - nos involucra al dejarnos ubicados en una dimensión universal. Gradualmente, los lectores vamos siendo introducidos en un relato en el que el valor de tal se desdibuja y una Voz implacable nos lleva y sacude a través de una historia cuya mirada está impregnada de desesperanza sobre el ser humano.

La historia que sigue es tan real como podáis serlo vosotros. Sucedió aquí como podría haber sucedido en cualquier otro sitio. Sería demasiado fácil pensar que ocurrió lejos. Los nombres de los individuos que la pueblan no tienen la menor importancia. Podrían cambiarse. Podrían sustituirse por los vuestros. Sois tan parecidos, surgidos del mismo molde inalterable... Estoy seguro de que tarde o temprano os haréis una pregunta lógica: ¿Fue testigo de lo que nos cuenta? Os respondo: Sí, lo fui. Como vosotros, que quizás no quisisteis verlo. Vosotros nunca queréis ver. Yo soy quien os lo recuerda. Soy el que molesta. El que no se pierde detalle. Lo veo todo. Lo sé todo. Pero no soy nada, y eso es lo que pienso seguir siendo. No soy ni hombre ni mujer. Soy la voz, nada más. Os contaré la historia desde la sombra. (pp. 9-10)

Con el tema de los refugiados como marco, de las migraciones de pueblos que denuncian años de colonización y sometimiento desplazándose en pos de una búsqueda concreta y simbólica de resarcimiento y que, en vez de ello, encuentran muros, costas inaccesibles y fronteras infranqueables, Claudel logra en esta obra escenificar el lado más oscuro de la humanidad. Pero también los intereses económicos que prevalecen sobre la identidad de los pueblos y los valores solidarios, el poder invisible y anónimo que pulsa sobre el acontecer cotidiano, y el alejamiento de la naturaleza y sus señales de alarma, integrarán la representación, que deja planteada una alusión a los malestares más recurrentes y dañinos de la civilización actual. 
Hacéis correr por doquier grandes torrentes de lodo. El odio es vuestro alimento, la indiferencia vuestra brújula. Sois criaturas del sueño, siempre dormidas, hasta cuando creéis que estáis despiertas. Sois el fruto de unos tiempos soñolientos. Vuestras emociones son efímeras, como mariposas calcinadas por la luz del día cuando apenas han salido del capullo. Vuestras manos moldean vuestra vida con una arcilla seca e inconsistente. La soledad os devora. El egoísmo os engorda. Dais la espalda a vuestros hermanos y perdéis el alma. Vuestra naturaleza está hecha de olvido. (p. 9)

Se diría que, en esta novela, humanidad y naturaleza son los máximos protagonistas: la naturaleza aparece regidora y representante de pasiones y circunstancias humanas.

Así, un volcán rugiente con un comportamiento aparentemente imprevisible compone y preside la isla: el Brau ('bravo' en algún idioma) se enfurece o llora, brama, da vida, pero también la quita. Vigilante y amenaza, forma parte del escenario de manera más o menos silente, pero constante, señalando ciertos momentos como especialmente significativos y sugiriendo mensajes o denunciando pactos fatales ante la ceguera simbólica de los habitantes del lugar. Es testimonio de lo que se pretende ignorar, ocultar.

Como Vulcano, el antiguo dios romano que recibe ofrendas para aplacar su ira, en este caso se pretenderá que el volcán degluta la verdad, como si ello fuera posible.

La lúgubre aparición de tres cuerpos en una playa de la isla, testimonio del fracaso de la búsqueda de horizontes de salvación - y de la sensibilidad y de la fraternidad entre las personas-, deja planteado el punto de partida. (En el Río de la Plata esta escena no nos resulta ajena y nos remite a lo traumático de una herida abierta que nos perdura.) 
En esa isla escarpada, que pretende dar la espalda a la muerte, que minimiza el lugar para sus muertos y los entierra de pie, la presencia de estos mudos extranjeros desafía a sus habitantes, que luchan con su propio desconcierto ante lo desconocido -o lo que quieren desconocer-. Ofrecerles sepultura sería una manera digna del reconocimiento de una realidad de la que ellos mismos también forman parte, aunque se empeñen en negar; pero entonces prevalecen el miedo y la vivencia de amenaza a una supuesta y precaria paz.

En torno a esto es que, como en un patético desfile, empiezan a emerger los personajes de la comunidad. Nominados en función de los roles y lugares que ocupan en ella, muestran dificultad para tomar distancia de la función concreta, entrelazan anonimato y universalidad, conspiran, interpelan. A través de ellos queda representado un pueblo que puede ser cualquier pueblo o comunidad de estos tiempos.

$Y$ algunos de ellos se autoasignan la potestad de componer un tribunal de facto que defina y dictamine el suceder de los hechos consecuentes.

Representan lo viejo y lo nuevo, la esperanza y la desesperanza; referentes antagónicos o complementarios, caducos o vigentes, que muestran al poderoso, a la vez que al frágil y al sumiso, en función de víctimas no reconocidas que paradójicamente adoptarán cada vez más una presencia incisiva, ineludible, y que irán instalándose progresivamente en el espacio compartido y en el interior de cada uno.

Lo que podría ser la sabiduría de los mayores aparece como miedo y resistencia al cambio. La Vieja, antigua maestra que ocupa un lugar de poder por el conocimiento del discurrir de las vidas de los lugareños, se ve incomodada por su sucesor: el actual Maestro, representante de lo novedoso, lo foráneo, y de la búsqueda de la verdad como propósito.

Vivido como amenaza al supuesto equilibrio reinante (equilibrio precario, frágil, rígidamente conservador y basado en el sostenimiento de 
acuerdos y convenciones tradicionales implícitos), el Maestro será objeto de la reacción conservadora.

Pero también circularán otras figuras, vinculadas a distintos aspectos: el Alcalde, representante de la comunidad, que ostenta también el poder por la posesión de los medios para la pesca como principal actividad económica de la isla; el Emperador, quien lidera el diligenciamiento de dichos medios y es diestro conocedor de la técnica de la pesca del pez espada y mano derecha del Alcalde; el Médico, quien, como supuesto representante de la función científica, tiene asignada la potestad de demorar a la muerte; y el Cura, referente espiritual del pueblo y depositario de la ilusión de un más allá de este mundo, a la vez que de la duda intrínseca...

Las constelaciones de relacionamientos que se van conformando ante los ojos lectores entre estos personajes (y otros más comunes, pero no menos importantes) no serán aleatorias o casuales, sino que irán conduciendo al sórdido destino de la trama. Generan un escenario donde, más adelante, quedarán planteadas las condiciones para la aparición de otro personaje, siniestro: el Comisario, tan ajeno al pueblo como efímero, pero útil y funcional a la concreción de lo que venía quedando esbozado. Antes, no existía. Después, dejó de existir. Es el máximo exponente de una incomodidad colectiva que ya se venía planteando, pero que no se lograba enunciar; su presencia sella aquello de lo que internamente la comunidad no se podía hacer cargo. Viene a mostrar los aparentemente irreversibles designios de la deshumanidad.

Si bien esta novela sostiene un sabor amargo perturbador, una mirada dolida y penosa hacia el malestar en este momento de la civilización, el lector podrá conectar con cierta perspectiva esperanzadora, que queda insinuada a través de los sueños del Médico, cual triunfo del encantamiento órfico sobre el can Cerbero. Estos sueños de angustia permiten rescatar al personaje en su humanidad, en el registro de un sentimiento 
de culpa insoslayable ante lo que, como habitante de estos tiempos, no puede dejar planteada indiferencia o ilusión de ajenidad.

Y en un humano gesto, la Voz se despide de este modo:

Bueno, ya casi está. [...] Voy a retroceder a gatas y marcharme.

Voy a volver a la sombra.

A disolverme en ella.

Os habré dejado las palabras. Me llevaré los silencios.

Voy a desaparecer.

Os prometí que solo sería la voz.

Nada más.

El resto es humano y os concierne a vosotros. (p. 201) 